\title{
Long Memory in Song Learning by Zebra Finches
}

\author{
Yasuko Funabiki and Masakazu Konishi \\ Division of Biology, California Institute of Technology, Pasadena, California 91125
}

Young songbirds use memorized tutor songs as templates to shape their own songs. This process requires control of voice by auditory feedback. We prevented zebra finches from hearing their own vocalizations by exposure to loud noise after $35 \mathrm{~d}$ of age, before which they had been reared with song tutors from birth. When the noise stopped at 102-200 d of age, the birds sang unstable and noisy song syllables that did not resemble the tutor syllables. The similarity to the tutor syllables steadily increased until the time of song crystallization $\sim 30$ $\mathrm{d}$ later. These findings show that the memory of tutor syllables survives auditory perturbations during the period when it is normally recalled and that zebra finches can use the memory well after the normal period of song development. The temporal order of syllables resembled the tutor model only in birds released from the noise before $80 \mathrm{~d}$ of age but not in older birds. Thus, different schedules and processes may govern the learning of syllable phonology and syntax.

Key words: zebra finch; memory; learning; auditory feedback; sensory phase; sensorimotor phase

\section{Introduction}

Many animals use complex sounds for communication, but few of them must learn to produce them. Humans and songbirds belong to the small group of animals that learn vocal signals. A birdsong consists of sound components such as notes and syllables and silent intervals between them. Song develops gradually through variable vocalizations toward a stable or crystallized form. Young birds memorize songs before they are old enough to sing, because their song tutors, like their fathers, cease to sing after the breeding season. Birds that are isolated after having heard a tutor song can reproduce it later without hearing it again (Marler and Peters, 1981, 1982). Thus, song learning consists of two stages, memorization or sensory phase and reproduction or sensorimotor phase. Birds use the memorized tutor song as a template to shape their vocal output, because they cannot reproduce the song if they become deaf before the onset of singing (Konishi, 1965). The sensory phase has been extensively studied in species in which the two phases do not overlap, such as whitecrowned sparrows and song sparrows (Marler and Tamura, 1964; Marler, 1970; Marler and Peters, 1987). These studies clearly showed that young songbirds could reproduce the tutor song long after hearing it only during the sensory phase. These findings led to the notion of long memory in song learning (Marler and Peters, 1982). These studies periodically monitored vocalizations to see whether and when the birds began to reproduce any part of the tutor song. The possibility of comparing voice with the song memory arises as soon as birds begin to vocalize. This process can occur well before we can detect any signs of song imitation (Tchernichovski et al., 2001). It may be that birds begin to use the song

\footnotetext{
Received Feb. 6, 2003; revised June 4, 2003; accepted June 4, 2003.

This work was supported by National Institutes of Health Grant NH55984. We thank Ofer Tchernichovski for help with sound analysis, Allison Doupe and Teresa Nick for critically reviewing previous drafts of this manuscript, and Anthony Leonardo and Kazuo Funabiki for help with the hardware and software used in the present project.

Correspondence should be addressed to Dr. Masakazu Konishi, Division of Biology 216-76, California Institute of Technology, Pasadena, CA 91125. E-mail: konishim@its.caltech.edu.

Copyright $\odot 2003$ Society for Neuroscience $\quad$ 0270-6474/03/236928-08\$15.00/0
}

memory early and continue to do so until song is crystallized. The term "long memory" would not be appropriate for such a process. Thus, a rigorous proof for long memory requires control of access to the song memory during vocal development.

The question is how to control the bird's use of song memory during the period of testing. The techniques include reversible blocking of either hearing or singing to break the vocal-auditory feedback loop (Nottebohm, 1969; Pytte and Suthers, 2000). We prevented young zebra finches from hearing their own voice by exposing them to continuous masking noise during and beyond the normal period of the sensorimotor phase. After we stopped the noise at 102-200 d of age, the birds gradually developed song syllables that resembled the tutor syllables. Thus, zebra finches can retain and recall the memory of individual tutor syllables well beyond the age at which song learning normally subsides. In contrast, the birds exposed to noise beyond $80 \mathrm{~d}$ of age failed to reproduce the syllable sequences of their tutors. Thus, different schedules and processes may govern the learning of syllable phonology and syntax.

\section{Materials and Methods}

Animals. Two pairs of adult Bengalese finches and five pairs of adult zebra finches were obtained from our breeding colony. Each breeding pair was housed in a sound attenuated chamber. Eggs of Bengalese finches were exchanged for those of zebra finches. We used the Bengalese finches as tutors for young zebra finches, because we wanted to discriminate between learned and unlearned components in the songs of the pupils. Young zebra finches might innately produce syllable phonology and syntax that resemble those of their conspecific tutors. Bengalese tutors can reduce this ambiguity, because their syllable syntax and some of their syllable types do not occur in the song of zebra finches. Thus, if zebra finch pupils sing songs containing these features, they must have copied them from their foster fathers.

All young birds were raised either with their biological parents or with foster parents until $35 \mathrm{~d}$ of age. Male nestlings of both experimental and control groups were removed and isolated in individual sound attenuated chambers. Thereafter, the control birds $(n=9)$ were kept in quiet chambers, whereas the experimental birds $(n=21)$ were exposed to 
Table 1. Birds used in experiments

\begin{tabular}{llll}
\hline Tutors & Exp-birds & Exp2-birds & Control birds \\
\hline Bengalese 1 & 4 & 7 & 3 \\
Bengalese 2 & 3 & 0 & 3 \\
Zebra finch 1 & 3 & 0 & 3 \\
Zebra finches 2-5 & 4 (1 per tutor) & 0 & 0 \\
Total & 14 & 7 & 9 \\
\hline
\end{tabular}

noise. Of these, 14 Exp-birds were used to study the effects of long periods (102-200 d) of noise exposure on both syllable phonology and syntax (compare Fig. 4a) and seven Exp2-birds were used to test the effects of shorter periods (53-90 d) of noise exposure on the development of syllable syntax (Table 1).

Auditory perturbation. The aim of this work required methods to prevent the birds from using the memory of tutor songs during a particular period. Thus, control of either hearing or vocalization would achieve this purpose. An ideal method for reversible control of auditory feedback would be electronic (Leonardo and Konishi, 1999). This technique is unsuitable for an early phase of song development, because the song is both too soft and variable to determine the moment when delayed feedback starts. We exposed all experimental birds to sustained noise, $110 \mathrm{~dB}$ (A) sound pressure level (SPL), day and night. [(A) refers to a filter setting in sound measurement; $\mathrm{dB}(\mathrm{A})$ means that this filter setting was used to obtain $\mathrm{dB}$ values.] We chose this sound level to avoid permanent damage to the inner ear hair cells. Avian hair cells regenerate after destruction by loud noise or drugs (Corwin and Cotanche, 1988; Ryals and Rubel, 1988; Woolley and Rubel, 1999). However, it is not known whether they regenerate more than once. We measured the sound pressure levels of this noise with a Brüel and Kjaer 1 inch microphone in conjunction with a Brüel and Kjaer microphone amplifier. This noise level not only raised threshold but also assured a relatively fast and complete recovery of auditory sensitivity after the cessation of noise (Fig. 1).

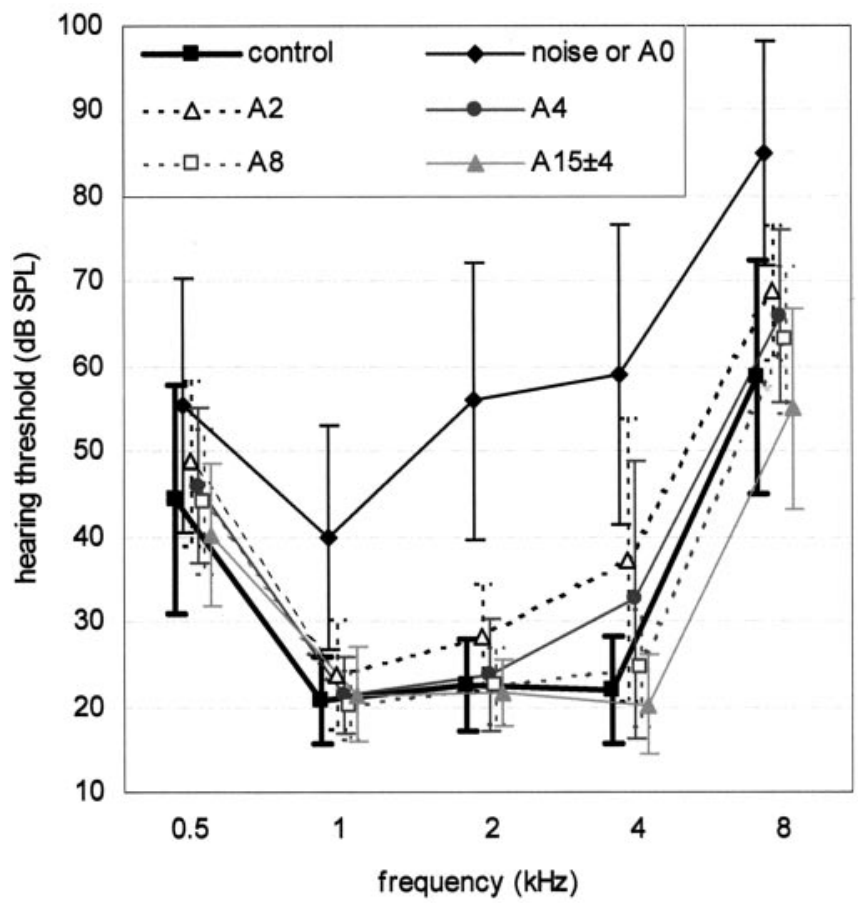

Figure 1. Changes in hearing thresholds after release from noise. Hearing thresholds of Exp-birds ( $n=14)$ to pure tones $(0.5,1,2,4$, and $8 \mathrm{kHz}$ ) were measured behaviorally and compared with those in control birds $(n=9)$. Plotted (symbols and bars) are the means and SDs. Symbols are explained in the inset. A2, 2 d after release from noise. The speed of recovery was different for different frequencies: the mean threshold for $1 \mathrm{kHz}$ was different from that of the controls on the day of release from the noise but no longer so $2 \mathrm{~d}$ after release, whereas the mean thresholds for 2 and $4 \mathrm{kHz}$ took $4 \mathrm{~d}$ to become indistinguishable from those of the controls.
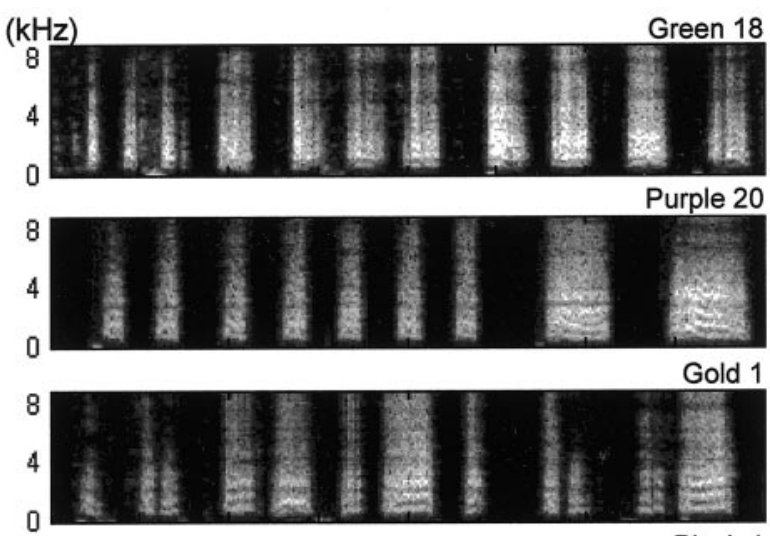

Black 1

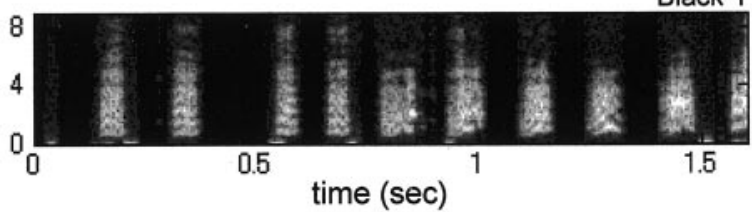

Figure 2. Songs recorded shortly after release from noise. Birds heard tutor songs until $35 \mathrm{~d}$ of age and were exposed to noise for different durations. Songs recorded within $3 \mathrm{~d}$ after release from noise consisted of syllables and silent intervals spaced more or less regularly. The syllables were noisy and lacked most of the elaborate sound patterns contained in the tutor songs. These abnormalities appeared regardless of the age of release from noise: $75 \mathrm{~d}$ for Green 18, $106 \mathrm{~d}$ for Purple 20, $109 \mathrm{~d}$ for Gold 1, and $122 \mathrm{~d}$ for Black 1.

We measured the auditory thresholds of nine control birds and 14 Exp-birds (Fig. 1). The methods of measurement had to be simple and fast for the Exp-birds, because repeated exposure to test tones might affect song development. We observed each bird in a dark sound attenuated chamber with a night vision device. The test signals were tones of $0.5,1,2,4$, and $8 \mathrm{kHz}$. Sound pressure levels varied from $10 \mathrm{~dB}$ SPL to 100 $\mathrm{dB}$ SPL in $5 \mathrm{~dB}$ steps. The hearing threshold is the lowest sound level to which the bird responded. The reactions to these signals were sudden movements or calls or both. These methods are reliable, because the audibility curve for the control birds is very similar to those obtained by other techniques (Ryals et al., 1999).

Song recording. We recorded songs in two sound attenuated chambers using Optimus 33-3022 microphones (Radioshack, Fort Worth, TX). We used a software-based sound level detector to enable a computer to start recording vocal activities (Leonardo and Konishi, 1999). Sounds were filtered (20 kHz cutoff), sampled at $40 \mathrm{kHz}$, and recorded directly onto the hard disc. Vocalizations of the control birds were recorded almost every day from before $35 \mathrm{~d}$ of age until the beginning of singing and less frequently afterward. Monitoring of several Exp-birds at day 35, just before the noise exposure began, did not indicate any singing. The songs of experimental birds were not recorded during noise exposure, because even a short period of hearing their own vocalizations could defeat the purpose of the study. However, a small surveillance camera placed close to the bird's cage within the sound chamber recorded the bodily postures and beak movements associated with singing. Furthermore, we removed experimental birds for song recording after different durations of noise exposure. These birds always began to sing shortly after they were transferred to the recording chambers, indicating that they had been singing during noise exposure (compare Fig. 2). Other behaviors of these birds such as vigorous bathing, preening, and rapid flying maneuvers indicated that the noise did not distress them. Recordings were made frequently after release from the noise and during the period of change in song and less frequently as song crystallized.

Analysis of phonology. We used Sound Analysis 2.08 (Tchernichovski et al., 2000) to quantify the similarity of phonology between tutors and pupils. The default setting of Sound Analysis is adjusted for the song of zebra finches at the Rockefeller University. The song of Bengalese finches required a different setting. However, we used the same setting for the 
controls and experimental birds that heard the same tutor. The analyzed recordings (song files) were $1000 \mathrm{msec}$ in duration for tutors and 3000 msec for pupils. We adjusted these durations according to the positions of syllables in the sample. The longer sample from pupils helped reduce variability in overall similarity scores. We obtained mean similarity scores for 10 randomly selected song files per bird per sampling day. We recorded at least 50 song files from each tutor.

Analysis of syllable order. We randomly selected from each bird 50 songs containing 1500-2000 syllables. We used Sound Analysis 2.08 to match each tutor syllable to a pupil syllable. Analysis of syllable syntax required methods that are not available in Sound Analysis. We calculated the transition probability of every pair of syllables and compared the distributions of probabilities between the tutor and pupil syllable sequences as shown in Table 2. Here, a and $\mathrm{b}$ are syllables and aabbaabba and abababab indicate syllable orders. In Table $2, a$ and $b$ in the left column are leading syllables and those in the top row are following syllables. The numerator in each cell is the number of transitions from one syllable to another, and the denominator is the total number of transitions from each leading syllable. The sum of probability for each row is 1 . We compared the two contingency tables to see the degree of overlap between the two sequences. Thus, because a to $b$ transition probability is $2 / 4$ in the tutor and $4 / 4$ in the pupil, the overlap is $2 / 4$. Because the probability from $b$ to $a$ is $2 / 4$ for the tutor and $3 / 3$ for the pupil, the overlap is also $2 / 4$. We used the relative frequencies of different syllables in the pupil's song to weigh the overlaps such as $2 / 4 \times 4 /(4+4)+2 / 4 \times 4 /(4+4)=$ $1 / 2$, which is the measure of similarity for the above tutor-pupil pair. This procedure makes the sum of weighted overlaps 1, when the tutor and pupil sequences are identical. Each tutor syllable matches a pupil syllable in the above example. This method does not, however, ignore unmatched syllables. These obviously reduce the degree of similarity.

\section{Results}

It is well known that some features of species-specific songs appear in both deaf birds and birds raised in isolation (Konishi, 1964; Price, 1979; Marler and Sherman, 1985). Because this ability can confound the study of song learning, we used Bengalese finches as song tutors for the zebra finches that we used for comparison of both syllable phonology and syntax. The song of Bengalese finches contains syllable types that seldom occur in the song of zebra finches. Therefore, the Bengalese-like features in the syllables of foster-reared zebra finches are because of learning. In a separate group, we used young birds' own fathers as song tutors for comparison. Both the control and experimental birds had spent the first $35 \mathrm{~d}$ from birth with their own parents or with Bengalese foster parents and were transferred to individual sound attenuated boxes at $35 \mathrm{~d}$ of age. We chose this age because young zebra finches are known to memorize tutor songs by this age (Immelmann, 1969; Böhner, 1990; Jones et al., 1996). All Exp-birds were exposed to continuous broadband noise of $110 \mathrm{~dB}$ (A) SPL from $35 \mathrm{~d}$ of age to a mean age of $129 \mathrm{~d}$ (range, 102-200 d). The sensorimotor

$(\mathrm{kHz})$
Table 2. Calculation of similarities in syllable transition probabilities

\begin{tabular}{|c|c|c|c|c|c|c|c|c|c|}
\hline \multicolumn{3}{|c|}{ Tutor $=$ aabbaabba } & \multicolumn{3}{|c|}{ Pupil = abababab } & \multicolumn{4}{|c|}{ Overlap between two tables } \\
\hline & a & b & & a & b & & $\mathrm{a}$ & b & Sum \\
\hline a & $2 / 4$ & $2 / 4$ & a & 0 & $4 / 4$ & a & 0 & $2 / 4$ & $2 / 4$ \\
\hline b & $2 / 4$ & $2 / 4$ & b & $3 / 3$ & 0 & b & $2 / 4$ & 0 & $2 / 4$ \\
\hline
\end{tabular}

Here, $a$ and $b$ are syllables and aabbaabba and abababab indicate syllable orders. The left column shows the leading syllables, and those in the top row are following syllables. The numerator in each cell is the number of transitions from one syllable to another, and the denominator is the total number of transitions
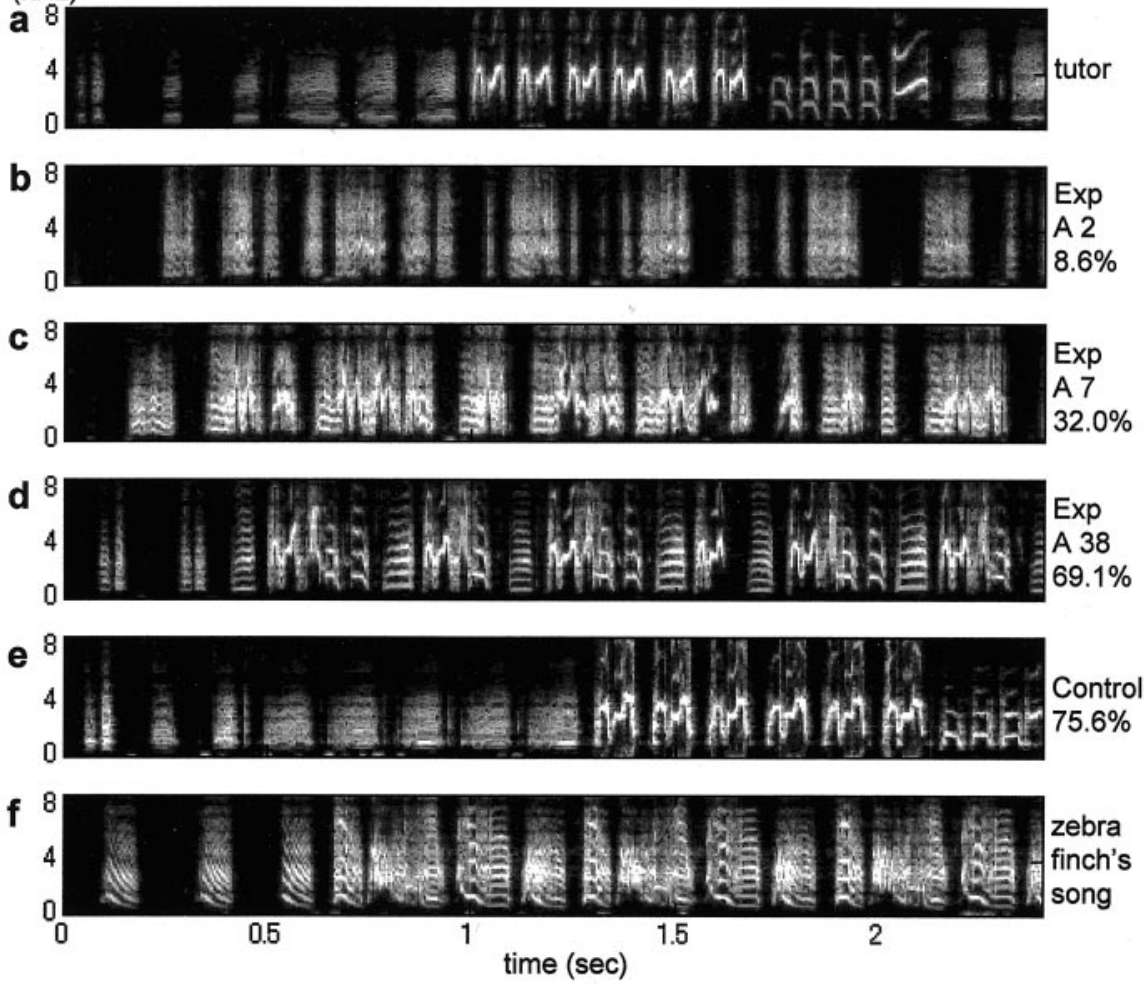

Figure 3. Gradual emergence of memorized tutor syllable structures. Unstable and noisy syllables became more stable and after release (A2), the mean similarity score (\%) seldom becomes 0 because of resemblances by chance. $c$, Song of the same bird $7 \mathrm{~d}$ after release (A7). $d$, Thirty-eight days after release. Note how the mean similarity increases with time. $e$, Song of a zebra finch pupil that heard the same Bengalese tutor, but not exposed to noise. $f$, Song of a zebra finch for comparison.

phase of song learning normally occurs between 40 and $80 \mathrm{~d}$ of age, and song crystallizes by $90 \mathrm{~d}$ (Zann, 1996). Therefore, the period of noise exposure covered more than the normal period of song learning in this species.

\section{Effects of noise on auditory threshold}

We used behavioral methods to measure the hearing sensitivity of both control and Exp-birds. Shortly after release from the noise, the Exp-birds had higher hearing thresholds than the controls for all frequencies tested (compare Fig. 1). The auditory thresholds of the Exp-birds recovered with time. The speed of recovery was different for different frequencies: the mean threshold for $1 \mathrm{kHz}$ was different from that of the controls on the day of release from the noise $(p<0.005)$ but no longer different $2 \mathrm{~d}$ after release $(p<0.240 ; t$ test), whereas the mean thresholds for 2 and $4 \mathrm{kHz}$ were still different from those of the controls $2 \mathrm{~d}$ after release ( $p<0.039$ for $2 \mathrm{kHz}$ and $p<0.015$ for $4 \mathrm{kHz}$; $t$ test) but indistinguishable from the controls after $4 \mathrm{~d}$ ( $p<0.68$ for $2 \mathrm{kHz}$ and $p<0.07$ for $4 \mathrm{kHz}$; $t$ test). 

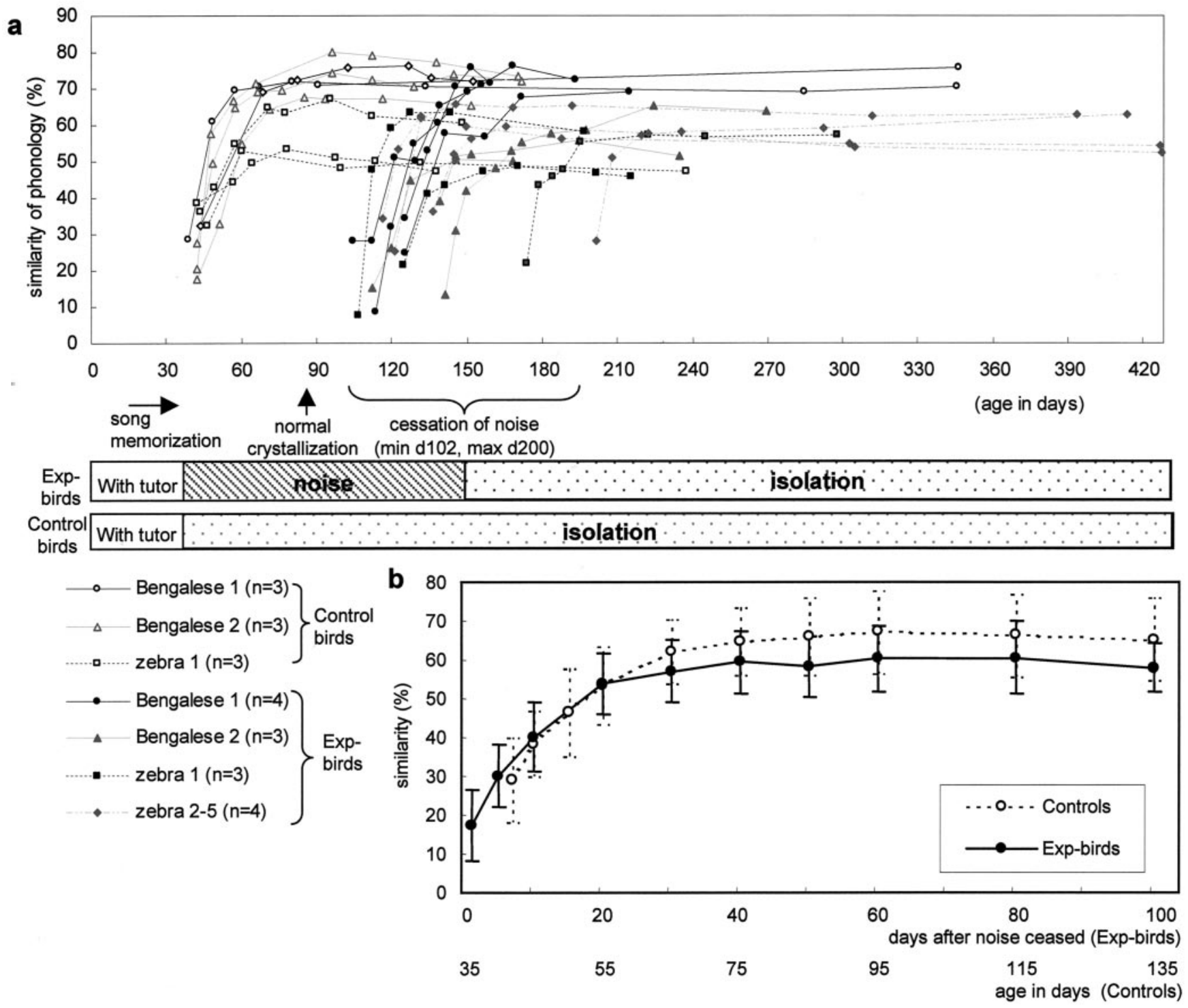

Figure 4. Time course of changes in similarity in syllable structure. a, All the birds in both control and experimental groups were reared by their biological (zebra finch) or foster (Bengalese finch) parents until $35 \mathrm{~d}$ of age. Then, the control birds were individually isolated to develop their song from memory. The Exp-birds were exposed to continuous broadband noise in individual sound isolation boxes between 35 and $129 \pm 27 \mathrm{~d}$ of age. After their release from the noise, all of these birds developed syllables resembling the tutor model. Open symbols show the similarity score at each sampling day in the controls, and closed symbols show that in the Exp-birds. The same symbols and lines are used for multiple pupils raised by the same tutor, including two Bengalese and five zebra finch tutors. $b$, Summary of similarities in syllables. This figure plots the means and SDs of the curves in $a$ to show the general trends. Although the Exp-birds had a lower mean similarity at the time of song crystallization than the controls, the similarity increased at almost the same rate as in the controls.

\section{Reproduction of tutor syllables from memory}

We will first describe the ability of the Exp-birds to reproduce tutor syllables after varying periods of noise exposure. Their syllables, as recorded soon after release from the noise, were unstable, noisy, and highly abnormal in general (Fig. 2). The syllables of all Exp-birds contained these abnormalities regardless of the age at which they were released from the noise. Syllables with more distinct structures emerged in songs recorded at later dates (Fig. $3 c, d$ ). We quantified the similarities in syllable phonology between tutors and their pupils using Sound Analysis 2.08 (Tchernichovski et al., 2000). Figure $4 a$ shows the results from all birds; here, each curve shows changes in the mean similarity score of a bird as a function of days from the time of either the separation from the tutor (for controls) or release from the noise (for Exp-birds). The mean similarity scores of all control birds reached a plateau in $\sim 30 \mathrm{~d}$ after the separation from their tutors at $35 \mathrm{~d}$ of age. Different Exp-birds were released from the noise at different times. Nevertheless, their mean similarity scores increased almost as fast as those of the control birds. Note that the mean similarity score of an individual bird seldom goes below $10-20 \%$ or exceeds $70 \%$ in zebra finches. One hundred percent is unattainable because of individual differences in song that inevitably develop. In contrast, $0 \%$ is unattainable, because similarities can occur in unlearned components of syllables.

To compare the Exp-birds with the control birds as groups, we plotted the mean of mean similarity scores for each group as a function of days after either $35 \mathrm{~d}$ of age for the control birds or the day of release from the noise for the Exp-birds (Fig. 4b). We compared mean similarity scores between the control birds and Exp-birds that were raised by the same tutor to exclude the possible effects of differences in tutor songs on similarity scores. In both groups, song crystallized and the similarity to the tutor syl- 
lables reached a plateau in $\sim 1$ month. At the plateau level, the Exp-birds' syllables resembled their foster fathers with a mean similarity score of $60.3 \pm 3.2 \%$ (at $60 \mathrm{~d}$ after release from noise), whereas the syllables of the controls resembled those of the same fathers with a mean similarity score of $67.2 \pm 3.5 \%$ (at 95 d of age). However, this difference between the two groups is statistically not significant ( $t$ test; $t=1.402 ; p=0.183$ ).

\section{Development of overall temporal} pattern of song during noise exposure The songs of both zebra and Bengalese finches are composed of syllables of certain durations and silent intervals between them. This overall temporal pattern was already evident in the songs that the Expbirds sang shortly after release from the noise (Fig. 2). We randomly selected 20 syllables and inter-syllable intervals from six Exp-birds raised by Bengalese 1 and 2 tutors. The mean and SD of syllable durations and silent intervals of the Bengalese tutors were $75.3 \pm 23.1 \mathrm{msec}$ and $37.8 \pm 16.7 \mathrm{msec}$, respectively. The mean and SD of syllable durations and silent intervals of the six Exp-birds recorded shortly after release from the noise were $79.0 \pm 30.5 \mathrm{msec}$ and $99.7 \pm 55.1 \mathrm{msec}$, respectively. The mean and SD of syllable durations and silent intervals of the six Expbirds after song crystallization were $78.1 \pm 36.1 \mathrm{msec}$ and $36.5 \pm$ $21.0 \mathrm{msec}$, respectively. The mean syllable duration did not differ between the tutors and pupils at any time ( $p=0.482$ for shortly after release and $p=0.641$ after song crystallization; $t$ tests). However, shortly after release from the noise, the mean silent interval of the six Exp-birds was longer than that of the tutors $(p<0.0001 ; t$ test). After song crystallization, there was no difference in the mean silent interval ( $p=0.738$; $t$ test). MannWhitney $U$ tests of individual pupils with their tutors were consistent with the results of the $t$ tests.

\section{Effects of noise exposure on the development of syllable sequences}

The Exp-birds did not reproduce the order of syllables in the tutor song (Fig. 5). For the quantitative analysis below, we compared the same control birds and Exp-birds that we used for the analysis of phonology. These Exp-birds were released from the noise after $100 \mathrm{~d}$ of age. We calculated for each syllable the probabilities of each other syllable following and compared the distributions of probabilities between the tutor and pupil songs. When the tutor and pupil distributions matched perfectly, we assigned a similarity score of 1 . The overlap between the tutors and the Exp-birds was only $0.25 \pm 0.10$ compared with $0.67 \pm 0.16$ between the same tutors and the controls (Fig. $6 a$ ). These differences were statistically significant $(t=6.89$; $p<0.0001)$. The value $0.25 \pm 0.10$ is near random, because one would expect an overlap of $0.24 \pm 0.05$ if the pupil ordered syllables at random. We also tested whether the Exp-birds reared by their own parents might be able to copy the syntax better than those raised by Bengalese foster parents. Their performance was no better than those raised by Bengalese finches (i.e., controls, $0.59 \pm 0.13$; Exp-birds, $0.21 \pm 0.15$ ).

We used another criterion to determine the influence of the tutor syntax on the pupil's song. The presence or absence of syllable repetitions distinguishes the song of Bengalese finches from that of zebra finches (compare Fig. 5). If zebra finches raised by a Bengalese pair repeat syllables, the pupils have probably derived this trait from the tutor model. The Exp-birds developed and maintained a fixed sequence of syllables that resembled the species-specific syntax of zebra finches (such as abc) more than the Bengalese syntax (such as aabbbccc), whereas the control birds repeated the syllables like their foster father. We measured, therefore, the rate of syllable repetitions in the songs of fosterreared controls and Exp-birds. The Exp-birds repeated the syllables much less frequently than the controls (Fig. 6b). Removal of repetitive segments of the song reduced the syntactical difference between the two, although the difference was still significant $(p=0.014$ ) (Fig. 6c).

Having found the effects of noise exposure on the syllable syntax, we used an additional group of birds (Exp2-birds) to test whether the duration of noise exposure affects the retention of syllable sequences. The Exp2-birds $(n=7)$ were raised with tutors until $35 \mathrm{~d}$ of age and then exposed to noise. Five birds that were removed from the noise before $80 \mathrm{~d}$ of age reproduced the correct syllable orders of their Bengalese foster fathers (Fig. $6 d$ ). In contrast, two birds that were removed from the noise at or after $80 \mathrm{~d}$ of age failed to reproduce the tutor syntax.

\section{Discussion}

Animals, young and old, must memorize certain biologically important signals during some phase of their lives. Learning may occur once during an animal's lifetime, as in young salmon remembering the smell of their birthplace, or during every breeding season, as in ewes and their lambs remembering the smell of each other (Keverne, 1995). When the time of learning is restricted, it is called a critical period. In birdsong research, it is now generally agreed that the temporal boundaries of learning are not as critical as the name implies. Zebra finches that were raised in isolation could both memorize and reproduce a small number of tutor syllables after the normal age of song crystallization, which is $\sim 90$ d (Eales, 1985; Morrison and Nottebohm, 1993; Jones et al., 

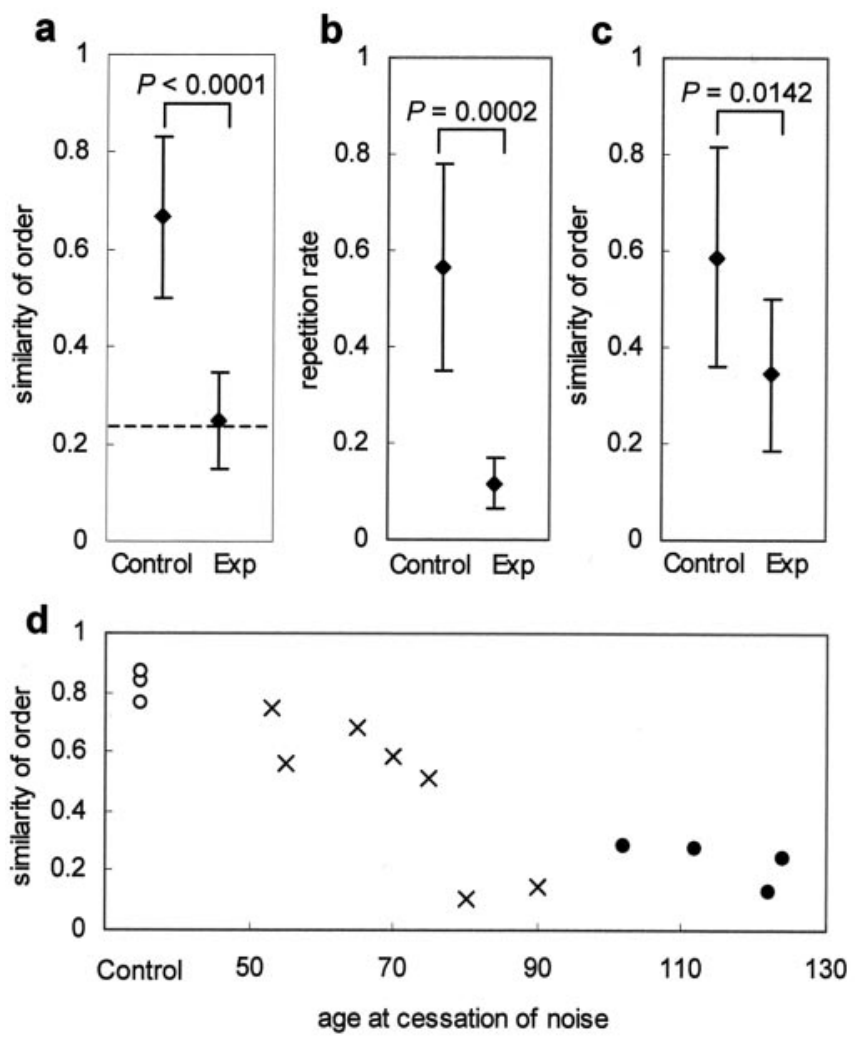

Figure 6. Inability of experimental birds to reproduce tutor syllable sequences. $a$, The mean similarity score of the Exp-birds was significantly lower than that of controls and similar to the random level ( $p=0.9474$ ). Dashed line indicates random level. $b$, The rate of syllable repetitions was different between the controls and Exp-birds. c, Removal of repeated syllables reduces the syntactical differences. Circles are means, and error bars are SDs. $d$, Similarity to tutor syntax declines sharply when birds were released from noise after 80 d of age. All 14 birds shown in $d$ were raised by the same foster parent (Bengalese 1). Open circles, Control birds; filled circles, Exp-birds; crosses, Exp2-birds.

1996). Furthermore, recent studies show that adult zebra and Bengalese finches retain the ability to modify song under experimental conditions. Adult birds may lose control of song in response to perturbation of auditory feedback or deafening. Such birds gradually recover the original song and even learn a new song after normal auditory feedback is restored (Leonardo and Konishi, 1999; Woolley and Rubel, 2002). The ability to restore the original song indicates that the birds remember it. This memory may also work like the template mentioned earlier. What is not known is the extent to which the previous experience of singing contributes to the restoration of the original song. Deafening caused much less deterioration to the song of 2- to 5-year-old zebra finches than to that of younger adults (Lombardino and Nottebohm, 2000). To our knowledge, no study has tested the storage of song memories while the vocal-auditory feedback loop was open.

The main aim of our work was to study the retention of song memories before vocal-auditory interactions occur by reversibly eliminating auditory feedback well before the birds started to sing. Thus, our work focused on the fate of the memory of a tutor song as it was formed during the sensory phase of song learning. Although restricted learning in our paradigm tells little, what the birds copied shows not only how long song memory remained but also how long the motor side of the song control system retained its plasticity. The syllables of the Exp-birds shortly after release from the noise lacked most of the fine features of the tutor syllables regardless of their age. However, the temporal pattern of these songs consisted of syllables of normal durations, although the silent intervals between them were much longer than those of the tutors. These songs were strikingly similar to those that zebra finches deafened in early ages produced in adulthood [Price (1979), his Fig. 4]. The syllables in Price's birds were noisy, but their mean duration ( $90 \pm 60 \mathrm{msec}$ ) was like that of normal adult zebra finches $(90 \pm 50 \mathrm{msec})$, and their mean silent intervals $(70 \pm 20 \mathrm{msec})$ were much longer than that of normal adult zebra finches ( $40 \pm 20 \mathrm{msec}$ ). Our Exp-birds also had syllables of normal durations and abnormally long silent intervals shortly after release from the noise. One of his birds was deafened at $17 \mathrm{~d}$ of age. This bird could have not retained this temporal pattern from previous singing and hearing experience, because it became deaf before it could sing. Zebra finches cannot sing before the axonal connections from $\mathrm{HVC}$ to the robust nucleus of the anterior neostriatum are established between 25 and $30 \mathrm{~d}$ of age (Akutagawa and Konishi, 1994). Thus, as Price (1979) pointed out, central pattern generators produced the overall temporal pattern of song in his deaf birds. The noisy syllables and long silent intervals of his deaf birds and our Exp-birds were attributable to the lack of control by auditory feedback. The subsequent development of syllables and silent intervals resembling the tutor models shows that zebra finches can retain beyond the normal age of song learning not only the memory of tutor syllables and their temporal spacing but also the ability to shape vocal output according to the memory.

What and where are the neural bases for plasticity in song learning? The song nuclei of zebra finches undergo both structural and physiological changes during the normal periods of both sensory and sensorimotor phases (Nordeen and Nordeen, 1988; Herrmann and Arnold, 1991; Aamodt et al., 1992; Akutagawa and Konishi, 1994; Livingston and Mooney, 1997; Harding et al., 1998; Kittelberger and Mooney, 1999). Some of these changes occur later than normal in birds raised in isolation (Wallhausser-Franke et al., 1995). If these changes are crucial for the timing of the sensorimotor phase, the inability to crystallize song during noise exposure might have delayed the changes. In this case, experience but not age changes the timing of neural transformation. It is also possible that these changes do not underlie the timing of song learning (Aamodt et al., 1995). Lesions of the lateral magnocellular nucleus of the anterior neostriatum (LMAN) disrupt the reproduction of tutor songs in young zebra fiches but not the maintenance of adult song. This discovery led to the view that the anterior forebrain pathway including LMAN mediates auditory feedback during the reproduction of tutor songs (Bottjer et al., 1984). However, recent studies show that lesions of LMAN in adult zebra fiches prevent the deterioration of song by artificial means such as deafening (Williams and Mehta, 1999; Brainard and Doupe, 2000a,b). LMAN is, therefore, actively involved in the maintenance of vocal plasticity in adulthood. The ability of the Exp-birds to develop a new vocal pattern at 102-200 d of age is consistent with this interpretation.

The most striking difference between the Exp-birds and the controls was the inability of the former to reproduce the tutor syntax. This inability was not because of species differences in tutor songs, for the Exp-birds that learned the songs of their own zebra finch fathers also could not reproduce the tutor syntax. Immelmann (1969) wrote that young zebra finches learned the phonology of syllables before their sequences. Also, the phonology of tutor syllables appears before the syntax during song development (Tchernichovski et al., 2001). Our control birds that were isolated from their tutors at $35 \mathrm{~d}$ of age reproduced both 
syllable phonology and syntax. The Exp-birds and their matched controls heard the same tutor song from birth to $35 \mathrm{~d}$ of age. Furthermore, the Exp2-birds that were released from noise before the age of $80 \mathrm{~d}$ reproduced the tutor syntax. We assume, therefore, that the Exp-birds had learned the tutor syntax before they were isolated. Many possible causes exist for the inability to reproduce the tutor syntax. The memory of longer signals may be harder to retain or recall. In humans, this difficulty is referred to as "the word length effects." Shorter spoken words are easier to remember than longer ones (Baddeley et al., 1975; NavehBenjamin and Ayres, 1986).

The effects of noise exposure may not be on memory storage or recall but on the plasticity of the song motor control system. Pytte and Suthers (2000) reported that paralysis of the syringeal muscles by botulinum toxin permanently disabled zebra finches to reproduce tutor syllables only when the drug was injected during the final phase of song crystallization. At other times, the birds could compensate for vocal abnormalities after the drug effects waned. The authors suggested a sensitive period in the organization of the song motor control system. This period (80-90 d of age) almost corresponds to the time when the ability to reproduce the tutor syntax declines. However, in both the paralysis and noise experiments, it is unclear whether the sensitive period depends on age or other factors such as the stage of song development in the paralysis experiment and the duration of noise exposure in the present work.

Behavioral and neurological studies suggest that different neural networks within the song system may control syllable phonology and syntax (Vu et al., 1994; Yu and Margoliash, 1996; Hahnloser et al., 2002). Both isolation and genetic experiments show the species specificity of syntax in birdsongs (Marler and Sherman, 1985; Güttinger, 1979). Lesions of song nucleus UVA (nucleus uvaeformis) affected the syllable syntax without altering the phonology in zebra finches (Williams and Vicario, 1993). In the Bengalese finch, bilateral lesions of the interfacial nucleus, which receives input from UVA, altered only the syllable syntax (Hosino and Okanoya, 2000). Perturbation of auditory feedback in adult zebra finches also seems to affect the syntax more than the phonology (Leonardo and Konishi, 1999). Thus, the inability to control vocal output by auditory feedback during song development may have different effects on the operation of neural networks for phonology and syntax.

In conclusion, zebra finches do have a long-term memory in song learning. The memory of tutor syllable phonology survived long periods of auditory perturbation and remained available for feedback control of song development. The results also show that the sensorimotor phase of song learning can occur at ages that are well beyond the normal period. Masking of auditory feedback differentially affected the reproduction of tutor syllable phonology and syntax, when the perturbation continued beyond $80 \mathrm{~d}$ of age.

\section{References}

Aamodt SM, Kozlowski MR, Nordeen EJ, Nordeen KW (1992) Distribution and developmental change in $[3 \mathrm{H}] \mathrm{MK}-801$ binding within zebra finch song nuclei. J Neurobiol 23:997-1005.

Aamodt SM, Nordeen EJ, Nordeen KW (1995) Early isolation from conspecific song does not affect the normal developmental decline of $N$-methylD-aspartate receptor binding in an avian song nucleus. J Neurobiol 27:76-84.

Akutagawa E, Konishi M (1994) Two separate areas of the brain differentially guide the development of a song control nucleus in the zebra finch. Proc Natl Acad Sci USA 91:12413-12417.

Baddeley AD, Thompson N, Buchanan M (1975) Word length and the structure of short-term memory. J Verbal Learn Verbal Behav 14:575-589.

Böhner J (1990) Early acquisition of song in the zebra finch, Taeniopygia guttata. Anim Behav 39:369-374.

Bottjer SW, Miesner EA, Arnold AP (1984) Forebrain lesions disrupt development but not maintenance of song in passerine birds. Science 224:901-903.

Brainard MS, Doupe AJ (2000a) Interruption of a basal ganglia-forebrain circuit prevents plasticity of learned vocalizations. Nature 404:762-766.

Brainard MS, Doupe AJ (2000b) Auditory feedback in learning and maintenance of vocal behaviour. Nat Rev Neurosci 1:31-40.

Corwin JT, Cotanche DA (1988) Regeneration of sensory hair cells after acoustic trauma. Science 240:1772-1774.

Eales LA (1985) Song learning in zebra finches: some effects of song model availability on what is learnt and when. Anim Behav 33:1293-1300.

Güttinger HR (1979) The integration of learnt and genetically programmed behaviour: a study of hierarchical organization in songs of canaries, greenfinches and their hybrids. Z Tierpsychol 49:285-303.

Hahnloser RH, Kozhevnikow AA, Fee MS (2002) An ultra-sparse code underlies the generation of neural sequences in a songbird. Nature 419:65-70.

Harding CF, Barclay SR, Waterman SA (1998) Changes in catecholamine levels and turnover rates in hypothalamic, vocal control, and auditory nuclei in male zebra finches during development. J Neurobiol 34:329-346.

Herrmann K, Arnold AP (1991) The development of afferent projections to the robust archistriatal nucleus in male zebra finches: a quantitative electron microscopic study. J Neurosci 11:2063-2074.

Hosino T, Okanoya K (2000) Lesion of a higher-order song nucleus disrupts phrase level complexity in Bengalese finches. NeuroReport 11:2091-2095.

Immelmann K (1969) Song development in the zebra finch and other estrilded finches. In: Bird vocalizations (Hinde RA, ed), pp 61-74. London: Cambridge University.

Jones AE, Ten Cate C, Slater PJB (1996) Early experience and plasticity of song in adult male zebra finches (Taeniopygia guttata). J Comp Psychol 110:354-369.

Keverne EB (1995) Olfactory learning. Curr Opin Neurobiol 5:482-488.

Kittelberger JM, Mooney R (1999) Lesions of an avian forebrain nucleus that disrupt song development alter synaptic connectivity and transmission in the vocal premotor pathway. J Neurosci 19:9385-9398.

Konishi M (1964) Effects of deafening on song development in two species of Juncos. Condor 66:85-102.

Konishi M (1965) The role of auditory feedback in the control of vocalization in the white-crowned sparrow. Z Tierpsychol 22:770-783.

Konishi M (1985) Birdsong: from behavior to neuron. Annu Rev Neurosci 8:125-170

Leonardo A, Konishi M (1999) Decrystallization of adult birdsong by perturbation of auditory feedback. Nature 399:466-470.

Livingston FS, Mooney R (1997) Development of intrinsic and synaptic properties in a forebrain nucleus essential to avian song learning. J Neurosci 17:8997-9009.

Lombardino AJ, Nottebohm F (2000) Age at deafebubg affects the stability of learned song in adult male zebra finches. J Neurosci 20:5054-5064.

Marler P (1970) A comparative approach to vocal learning: song development in white-crowned sparrows. J Comp Physiol Psychol 71:1-25.

Marler P, Peters S (1981) Sparrows learn adult song and more from memory. Science 213:780-782.

Marler P, Peters S (1982) Long-term storage of learned birdsongs prior to production. Anim Behav 30:479-482.

Marler P, Peters S (1987) A sensitive period for song acquisition in the song sparrow, Melospiza melodia: a case of age-limited learning. Ethology 76:89-100.

Marler P, Sherman V (1985) Innate differences in singing behaviour of sparrows reared in isolation from adult conspecific song. Anim Behav 33:57-71.

Marler P, Tamura M (1964) Culturally transmitted patterns of vocal behavior in sparrows. Science 146:1483-1486.

Morrison RG, Nottebohm F (1993) Role of a telencephalic nucleus in the delayed song learning of socially isolated zebra finches. J Neurobiol 24:1045-1064.

Naveh-Benjamin M, Ayres TJ (1986) Digit span, reading rate, and linguistic relativity. Q J Exp Psychol A 38:739-751. 
Nottebohm F (1969) The "critical period" for song learning. Ibis 111:385-387.

Nordeen KW, Nordeen EJ (1988) Projection neurons within a vocal motor pathway are born during song learning in zebra finches. Nature 334:149-151

Price PH (1979) Developmental determinants of structure in zebra finch song. J Comp Physiol Psychol 93:260-277.

Pytte CL, Suthers RA (2000) Sensitive period for sensorimotor integration during vocal motor learning. J Neurobiol 42:172-189.

Ryals BM, Rubel EW (1988) Hair cell regeneration after acoustic trauma in adult Coturnix quail. Science 240:1774-1776.

Ryals BM, Dooling RJ, Westbrook E, Dent ML, MacKenzie A, Larsen ON (1999) Avian species differences in susceptibility to noise exposure. Hear Res 131:71-88.

Tchernichovski O, Mitra PP, Lints T, Nottebohm F (2001) Dynamics of the vocal imitation process: how a zebra finch learns its song. Science 291:2564-2569.

Tchernichovski O, Nottebohm F, Ho CE, Pesaran B, Mitra PP (2000) A procedure for an automated measurement of song similarity. Anim Behav 59:1167-1176.
Vu ET, Mazurek ME, Kuo YC (1994) Identification of a forebrain motor programming network for the learned song of zebra finches. J Neurosci 14:6924-6934.

Wallhausser-Franke E, Nixdorf-Bergweiler BE, DeVoogd TJ (1995) Song isolation is associated with maintaining high spine frequencies on zebra finch LMAN neurons. Neurobiol Learn Mem 64:25-35.

Williams H, Mehta N (1999) Changes in adult zebra finch song require a forebrain nucleus that is not necessary for song production. J Neurobiol 39:14-28.

Williams H, Vicario DS (1993) Temporal patterning of song production: participation of nucleus uvaeformis of the thalamus. J Neurobiol 24:903-912.

Woolley SM, Rubel EW (1999) High-frequency auditory feedback is not required for adult song maintenance in Bengalese finches. J Neurosci 19:358-371.

Woolley SM, Rubel EW (2002) Vocal memory and learning in adult Bengalese Finches with regenerated hair cells. J Neurosci 22:7774-7787.

Yu AC, Margoliash D (1996) Temporal hierarchical control of singing in birds. Science 273:1871-1875.

Zann RA (1996) The zebra finch. Oxford: Oxford University. 